\title{
Aligning Equity, Engagement, and Social Innovation in Anchor Initiatives
}

\author{
Esteban del Rio and John Loggins
}

\begin{abstract}
Drawing on cultural studies and the practice of engaged learning and scholarship, this paper proposes a cultural approach to institutional transformation, which we argue necessarily follows anchor partnerships. The authors advance a model of cohesion and alignment among equity, diversity, and inclusion (EDI), community engagement, and social entrepreneurship commitments at colleges and universities. This centers on the notion of "joining" as an epistemology and a methodology in community and campus-based work to achieve the anchor mission. In addition to advancing a theoretical model, the authors draw upon theory in practice at the University of San Diego, where the Center for Inclusion and Diversity, Mulvaney Center for Community, Awareness, and Social Action, and the Changemaker HUB aligned their efforts to approach student learning, community empowerment, and economic development through a cohesive lens.
\end{abstract}

Keywords: joining; EDI; equity; diversity; anchor mission; inclusion; epistemology; selfreflection; cultural change

\section{Introduction}

Colleges and universities excel at getting the separations right. Academic Affairs is not the same, nor does it feel the same, as Student Affairs. Departments and schools maintain different course requirements. We enforce the boundaries and justify the atomization of working campus units with ideals such as faculty governance, administrative organizational charts, academic freedom, and reporting structures. Our terms to describe the operations of an institution, its units, divisions, and areas, rely on focused, profession-specific, specialized, functional, and necessarily separated work. Even the language attached to higher education in the popular imagination connotes division: town/gown; ivory tower/real world; theory/practice; thinking/doing. As complex organizations that focus on the generation and dissemination of knowledge, specialization holds benefits for achieving received notions of excellence. The refinement of expertise, the practice of authority, and the conferral of degrees all rely on a kind of distinction. As higher education attempts to change out of its elite guise, distinction continues to serve as a default logic, silently guiding actions that fortify separation.

We name these distinctions because we embody them. Those of us affiliated with universities must remember to explain acronyms and jargon specific to our campuses and disciplines that, far too often, slip from our tongues unintelligibly when in community settings. We defer to hierarchy in an embodied manner, physically moving to the background when august professors or executive level administrators engage with partners. Without much hesitation, we trade the letters after our name or institutional titles for the authority and deference they afford as we 
engage with non-academics. Separation informs our assumptions and habits, and shapes our behavior.

But how do we get the connections right?

Place-based anchor relationships in urban settings ask colleges and universities to rethink their commitment to separation and instead, focus on the work of connection. Anchor institutions in higher education are colleges and universities rooted in their communities, advancing democratic partnerships and investment in economic opportunity through collaborative relationships with various stakeholders. As anchor thinking develops, community-centered ideas and languages emerge and gain momentum, potentially outpacing our compartmentalized campus cultures. For this reason, anchor commitments may suffer the fate befallen many existing higher education diversity and inclusion initiatives: words outpacing action and symbols replacing embodiment and transformation. The competitive nature of contemporary higher education turns ideas into slogans, replaces long-form participatory collaboration into branding and staging strategies, and inclines itself toward window dressing. Alternatively, how can we embody the best community and equity-centered ideas that we put forth? How can we internalize anchor commitments so that they manifest in our habits and assumptions?

In what follows, we offer a set of ideas - an approach, a practice, and a model — that strengthen the anchor mission by articulating connections between equity work, contemporary social movements, community engagement, and social entrepreneurship. These areas represent the nexus of some of the most urgent challenges of our time. In order to confront such challenges, new ways of joining must be imagined. Anchor commitments mean that universities think of themselves as a part of the community. Too often, however, these commitments operate more in word than in deed. For a college or university to sincerely embody the anchor mission, we must confront the truth that many parts of our campuses continue to operate unchanged and distinct from communities where they operate. While more useful terms than "community" exist to describe actors who do not work for the university (grassroots partners, intermediaries, residentdriven organizations), we will refer to these parties as "community" or "community partners." We hope to confront the academy's unstated commitment to separation, despite the most generous proclamations or well-intentioned efforts to build relevance to the broader world, and hope not to reproduce the separations in our own writing here. The practice of joining with communities in democratic partnerships means that universities must reflect on how they transform. This transformation cannot occur through campus declarations, messages from the president, or the establishment of task forces, but through culture change: a process where universities reflect on their operational habits and assumptions and discern change in order to join authentically and mutually with communities.

\section{Join with Communities: An Approach and a Practice}

Culture change can only be realized if one takes culture seriously. Below, we articulate a cultural approach to institutional transformation. We focus on building a community of practice around the concept of "joining." We then proceed to offer a cohesion model to explore how to enact and embody change. These ideas create an agenda for radically realizing the anchor mission through deep, transformative confrontation with habits and assumptions that limit the collective impact 
that universities and communities can achieve together. Further on, we confront the challenges and opportunities, perhaps in some contexts obscured by institutional inertia, through a cultural approach, a community of practice, and a working model of cohesion.

\section{A Cultural Approach to Institutional Transformation}

We begin with a cultural approach as a framework for change, leading to alignment among equity, engagement, and social innovation spaces in higher education. These are the coordinates for our idea of achieving the anchor mission in higher education. In doing so, we align our efforts with scholars and practitioners at colleges and universities, whose work connects the academe and the community, from scholars of engaged learning to those articulating mutuality and democratic partnerships through the anchor mission. We also recognize the wisdom and expertise of community partners who shape these connections, sometimes offering critical assessments of the reflexes and hidden commitments of higher education (Reyes, 2016). We critically accept recent work in higher education scholarship and organizational behavior that has sought to build ideas and infrastructure to advance inclusive excellence. We hope that a cultural approach and integration with community engagement can lead to more fully realized equity agendas on and off campus. The conversations and initiatives from convening organizations such as the Coalition of Urban and Metropolitan Universities, The Democracy Collaborative, Campus Compact, and Imagining America serve as catalysts for our ideas here. This essay provides points of articulation with existing thinking and practice, and for some readers and contexts, a confrontation with sometimes self-imposed limitations of realizing the anchor mission and the institutional transformation it suggests.

A cultural approach draws generally on the social sciences. Students of traditional anthropology and sociology are familiar with the application of cultural models to different contexts. Here, we draw from the disciplines of communication and cultural studies to focus on the way ideologies, constructed through messaging, inform and shape cultural practices. This move also allows for a confrontation with the misconceptions around communication and culture that minimize their impact and application. Too often, culture is conceptualized as the expression of a way of life, and communication is seen as representing the world. Rather, from a communication and cultural studies view, culture creates and sustains a way of life, and communication (language, symbol systems, discourses) produce reality, rather than merely tell us about it. In communication, we "construct, maintain, repair, and transform reality" (Carey, 1989, p. 30). If communication holds a formative role for the production of reality through symbol systems and language, culture manifests those messages. This lifts communication and culture from limited roles of merely describing social reality and organizational behavior and focuses instead on the generative and determining features of expression and action in higher education.

Culture represents a whole way of life (Williams, 1989). Scholars understand it as the system of meanings, or mental frameworks, that different groups deploy to make sense of the world, in a process of negotiation and contestation (Hall, 1986). Culture organizes the world, through language and other symbol systems, manifesting in everyday practices where systems of meaning are maintained and negotiated. Cultural studies, as an academic field, takes such a notion of culture seriously, especially how it manifests in popular, vernacular forms. Lawrence Grossberg argues that cultural studies "is concerned with describing and intervening in the ways 
cultural practices are produced within, inserted into, and operate in the everyday life of human beings and social formations, so as to reproduce, struggle against, and perhaps transform the existing structures of power" (2010, p. 9). Ultimately, cultural studies seeks to create emancipatory knowledge, so that social actors can confront unequal power relations that often remain hidden beneath the common sense cultivated by dominant groups. This field of inquiry provides a foundation for how culture is a way of understanding higher education, and how to create changes to higher education, called upon by all of the community engagement, equity, and social innovation commitments gathered under the anchor umbrella.

A cultural approach to institutional transformation in higher education asks for a critical stance toward the systems of meaning that we deploy in order to make sense of our work, our campuses, and our communities. Such a move goes beyond calls for organizational change (Golom, 2018). Instead, it examines the taken-for-granted making of meanings that occurs at a cultural level. Academic, professional, and institutional culture becomes the terrain of transformation. Rather than defaulting to the repetitive cycle of introducing of new initiatives, trainings, or restructuring, a cultural approach seeks to focus on the habits and assumptions that arrive from our cultural sense-making, and thus determine our behaviors and attitudes. A cultural approach aims for a deeper process that addresses the conditions under which our work occurs and the purposes that guide our individual and collective actions. Conditions and purposes hold a determining effect on our attitudes, behaviors, and ideas. These conditions and purposes might arrive from a community, vernacular, or participatory context, or, as is often the default in higher education, they arrive from above, in administrative dictates, faculty lectures, and task-force recommendations. We can understand the former as conditions set "from below" and the latter as set in place "from above" drawing on existing hierarchical patterns in universities and communities. The anchor mission asks for a casting off of these strict hierarchies in order to create conditions and purposes together.

How, then, do we radically institutionalize the anchor mission? A cultural approach would consider how academic and professional habits and assumptions, informed by systems of meaning created from "below" or from "above," must change through democratic partnerships and reset from a logic of mutuality. First, however, it requires something of a confrontation with existing cultural patterns that define professionalism in higher education, from the professoriate to public affairs. Becoming an anchor institution cannot be the sole province of specialized practitioners and bold leaders. It must manifest in the whole institution's work, through a deep process of acculturation. Ultimately, taking up the anchor mission requires a culture change, through an ongoing process of reflection, discernment, acculturation, and action:

- Reflect on the habits and assumptions, conditions, and purposes that guide individual and institutional actions, attitudes, behaviors.

- Discern which of those support the anchor mission and those that undermine the anchor mission.

- Identify changes necessary in strategy, but also in work routines and mental frameworks (personal and professional habits and assumptions that inform individual and collective work, and the conditions and purposes of that work).

- Commit to collectively setting the purpose and creating the conditions for culture change. Do so by empowering faculty, staff, students, and most importantly, community partners. 
- Assess (it is most useful to discern outcomes and assessment for anchor commitments as part of the normal assessment procedure)

\section{- Repeat.}

This last point returns to the beginning of the cycle closes the loop for what should be an ongoing process. People always make meaning, and as flexible and mutable as culture can be, it also persists through the routines of everyday life.

The anchor mission must be considered as a call to transformation in higher education. Colleges and universities communicate often about innovation and transformation, but when does a deep re-evaluation occur at the cultural level? Such an endeavor requires radical commitment from executive-level leaders on a campus, and an acculturation with the support of their authority throughout an institution. In other words, those with responsibility must understand epistemologically (intellectually and professionally), but also ontologically the urgent need for fundamental change in higher education because of relationships with communities. They can thus co-construct those changes with the community, and hold the campus accountable for enacting change.

A cultural approach requires a kind of holism. Communities read universities as coherent wholes. If one part of the university undertakes serious anchor work, but other parts of the university rest on traditional power dynamics that locate higher education above and apart from a community's everyday life, campus leaders should expect distrust from the community and criticism from engaged faculty and students. If the community engagement office is doing everything right, but business service, facilities, or student affairs operates according to other logics, suspicion from on and off campus will fill the space in-between. Rather than add new anchor initiatives to existing operations, a cultural approach asks for a reckoning with existing operational logics and the assumptions that produce them, which may have previously excluded much of the anchor agenda. It also necessitates a reckoning with the history of the college or university's relationships and practices in communities, and a re-evaluation of the broader ontology of community.

We suggest that a target in undertaking a cultural approach to institutional transformation in anchor discussions has to do with a term we use in our work: joining. By building a community of practice around joining, universities can confront the separations they have relied upon and that persist in efforts to connect more democratically with the communities they interact with. Joining means that communities co-construct the purposes and conditions of cultural, economic, and political coordinated action - and that colleges and universities are within communities, not outside of them.

\section{The Practice of Joining}

When I don't know myself, I serve you. I when I know myself, I am you.

-Ramayana (Hindu Sanskrit Text)

Within the fields of Community Service-Learning and Community Engagement, critical analysis of how and why universities show up in community has helped the pedagogy evolve. In Tania 
Mitchell's essay “Traditional Vs. Critical Service-Learning” (2008), one can see how this evolution has and continues to be taken up by universities. Critical Service-Learning refocused the orientation of community engagement toward social justice and opened a conceptual window to explore and examine the university's role in both perpetuating injustice and creating justice. Critical Service-Learning sets the stage for joining as a cultural, community practice in anchor relationships.

Mitchell's (2008) review of community engagement literature examined traditional and critical service-learning models of community engagement. Mitchell notes three areas that differentiate Critical Service-Learning from the traditional, received view of service-learning: 1) all participants seek to redistribute power in the relationship, 2) the cultivation of authentic relationships, and 3) participants work from a social change perspective. These three intentional outcomes are woven into community-based learning course objectives, the pedagogy, and the reflective process. Mitchell presents a deliberate approach that is structured and attentive. We draw from Critical Service-Learning here as we advance joining, as the practice of joining represents a deliberate practice that is emergent and mindful. More than anything, joining requires the political and professional will to work with whatever emerges from partnerships, without defensiveness and with accompaniment.

To begin to understand the practice of joining, it is helpful to offer up a distinction between mindfulness and attentiveness. Most mature community engagement programs in higher education will rightfully say that they are very mindful when they enter and work with community partners. Service-learning, while still fraught with voyeuristic tendencies and savior complexes, stands as highly reflexive and mindful practice in productive, critical national conversations. It offers a productive lens to understand the practice of joining. Refining and parsing out attentiveness from mindfulness offers a clear way hold the traditional and critical service-learning pedagogy and step into a deep practice of joining.

Attentiveness entails the willful acts of gathering community input, recognizing community partners as co-educators, and building reflexivity about power and privilege, which often takes the form of student reflections. All these thoughtful and deliberate actions enable practitioners to create a container that can safely hold the partnership. We then ask our students to safely step out of their comfort zone in order to effectively and respectfully work with community partners. Approaching the community with a high level of attentiveness is a very caring and effective way to engage, and in no way impedes taking up a practice of joining. This attentiveness has helped grow service-learning pedagogy in a way that critically addresses vital systemic power dynamics in service-learning. Ultimately, these lessons have pushed universities into expanding equitable, democratic relationships with communities as anchor institutions.

Mindfulness turns attention to that which emerges from partnerships. It describes the willingness to notice, work with, and accept what emerges. That which emerges from mindfulness can be a myriad of things ranging from personal issues or biases to unexplored power dynamics. Mindfulness can open expansive vistas of understanding and new ways forward in partnerships. In any community engagement moment or partnership opportunity, thoughts, feelings, and ideas will inevitably emerge; being willing and deliberate about experiencing what emerges stands as the crux of genuinely joining with community. The willingness to turn our gaze inward and 
notice what is coming up for me requires participants to be vulnerable, open, and brave. It requires all to courageously step into discomfort/disruption and be willing to hold, to work through, and to accept what arrives. Joining requires this kind of mindfulness to suggest pedagogical insights, research data, and community possibilities to reach the overarching purpose in anchor partnerships: to join in community together to strive for social equity and economic justice.

Informed by mindfulness, joining beyond service-learning thus becomes both an epistemology and a methodology in community and campus-based work for equity and social justice. To join with each other on campus and in the community proposes a transformational intervention in diversity and what is known as community service spaces. We argue that a cultural approach, manifests inclusion of marginalized groups, seeks democratic partnerships in communities, and builds capacity to confront to the urgent challenges and opportunities facing communities and campuses from an anchor logic, and ultimately an anchor being. Such an approach joins lay foundations and pathways so that higher education can transform itself as it invites racial and ethnic diversity. Becoming the anchor institutions that we aspire to be will undoubtedly entail deep change that will potentially encounter reluctance, denial, and resistance. Leadership's ability to tether itself to its anchor purpose, hold steady in face of this resistance, and maintain the fortitude to examine the institution's internal dynamics that keep us from equity, justice, and connections will be the measure of how possible a culture change really is.

The most difficult work of leadership involves learning to experience distress without numbing yourself. The virtue of a sacred heart lies in the courage to maintain your innocence and wonder, your doubt and curiosity, and your compassion and love even through your darkest, most difficult moments... A sacred heart allows you to feel, hear, and diagnose, even in the midst of your mission, so that you can accurately gauge different situations and respond appropriately... That's what we learned about the sacred heart - the willingness to feel everything, everything, to hold it all without letting go of your work. (Heifetz \& Linsky, 2002)

To join is to invite and engage mindfully in community with others with a reflexive openness to the radical potential of connection prior to the work of collaboration. Leadership theory, a foundational discipline for community engagement, suggests that joining helps us turn our gaze inward, looking at ourselves in relationship to the community. It requires an openness to change. Accordingly, a cultural approach seeks to transform organizations and institutions by examining how we make sense of our work, and how that informs our habits and assumptions, to better navigate a hierarchical, globalized world. This change is vitally important when joining with those from underrepresented perspectives, distressed communities, subaltern groups, and others who have not set the existing terms of "partnership." To do so fully, joining must develop through communities of practice. These are "groups of people who share a concern or a passion for something they do and learn how to do it better as they interact regularly" (Wegner, 2006, p. 1). Communities of practice serve as a framework for knowledge-sharing, where members learn from each other through interaction, and engage in the development and evolution of the practice (Meltzer \& Martik, 2017). Actualized through interactional, reflective, situated, and collective communities of practice, joining leads to authentic, democratic, and equity-centered articulations of anchor work. The larger the community of practice, especially from those on campus who 
hold the most tightly to traditional models and institutional inertia, the greater the realization of the anchor mission.

\section{The Cohesion Model and Communities of Practice}

A community of practice for joining takes form through the notion of cohesion. Returning to the opening paragraphs of this essay, we see a cultural approach and joining as ways to build coherence and cohesion around the anchor mission, disrupting unstated cultural commitments to distinction and separation. The terrain of this work occurs in models and structures, that is, the conditions and purposes that inform cultural action. What is the form of the work? Who created it? From our experience at the University of San Diego, we argue that a cultural approach, where the practice of joining can thrive, leads to a cohesion model. The cohesion model builds communities of practice from disparate functions of the university and in partnership with communities. The notion of cohesion implies connections, alignment, unity, sharing power, truth-telling, repair(ation), healing, and negotiation. In our work, we aligned the following functions: equity, diversity, and inclusion (EDI), community engagement, and social innovation. Together, we created a new way of working, of aligning our budgets, of joining with community partners to create compelling moments of sharing, engaging instances of disagreement, and new possibilities for what we might undertake together to make our neighborhoods and our campus more equitable, just, and viable. While our campus holds mature, well-respected, and integrated community engagement and social innovation practices, the pulsing issues and engaged social movements around equity, diversity, and inclusion serve as our collective catalyst and conscience in undertaking the anchor mission.

\section{Equity, Diversity, and Inclusion as a Point of Departure for Anchor Work}

Among the broad aims of contemporary U.S. higher education, few present more yearning for change, hope for the future, increasingly vexing questions, and persistent frustrations than equity, diversity, and inclusion (EDI) in general, and racial justice in particular. For many years, higher education limited itself to advancing numerical diversity and "including" people of color and other minority groups into their existing logic. This logic is culturally specific, based in wealthy, white, or male perspectives, but treated as normal and universal. Including those from underrepresented and underserved perspectives into this logic leads to persistent experiences of marginalization. This same logic shows up in colleges and universities relationships with communities. More recent equity agendas and struggles for racial justice on campus reformulate diversity and inclusion by focusing the change not on the new bodies who encounter the university, but on the institutions themselves.

Campuses now seem to strive to realize both accessibility and equity with initiatives, plans, and declarations, resulting in infrastructures and models centralizing the work of the diversity office and diversity officer (Williams \& Wade-Golden, 2013). The recent formal professionalization of the chief diversity officer (CDO) through the National Association of Diversity Officers in Higher Education (NADOHE) holds promise to better establish diversity apparatuses at colleges and universities, which too often have various levels of responsibility but rarely any institutional authority. On the other hand, the CDO role can become a perceived solution to entrenched equity issues in the minds of campus leaders, creating a point of responsibility without directly 
confronting the university-wide inertia that made the CDO role necessary. In other words, the $\mathrm{CDO}$ or the hastily-assembled diversity office can obscure the deep cultural work necessary to realize equity in higher education, especially when the CDO is beholden to authority held by vice presidents and presidents, for whom the CDO is just another constituent. The CDO role can appear to be doing the work, much like some articulations of anchor partnerships, but the existence of the position does not necessarily guarantee that the campus undertakes reflection and ongoing discernment about diversity with transformation as the end goal.

Over the last three years, ground-shifting events and ideological disruptions have overtaken best practices and status-quo diversity agendas of most colleges and universities, led by racial and intersectional justice movements with their attendant lists of demands that emerged nationally in November 2015. The election of Donald J. Trump in 2016 caused an outpouring of anxiety and urgency around questions of identity and status on campuses and in communities. As of this writing, a policy agenda from the White House and Congress manifests implicitly, when not explicitly, from a politics of bigotry, misogyny, and nativism. These developments call urgently not for any quickly assembled diversity apparatus, but for a fundamental cultural engagement with the values and missions of colleges and universities. From Black Lives Matter to the "sanctuary campus" movement, EDI defines the most urgent challenges, opportunities, and hopes on our campuses and in our communities. This synergy calls for a cultural approach to EDI, particularly concerning the intersections with service-learning and social entrepreneurship. Both of these areas have benefited from productive energy, a progressive practice, scholarship, and institutional buy-in over the last 10 years, while EDI efforts face a wide gap between research and practice. The "demands" of 2015 made visible the chasm between higher education diversity management and the social-justice activism in communities with whom students connect through solidarity, modeling, and sometimes collective organizing.

Do such conflicts exist between the necessarily related practices of service-learning, social entrepreneurship, and EDI, especially in anchor work? In many ways, without EDI, servicelearning is reduced to volunteering and social entrepreneurialism functions as just another version of capitalism. Absent direct confrontation with the inequitable systems that community work and social entrepreneurialism hope to replace, those systems operate silently underneath a new veneer, now more insidious, in that they appropriate criticisms leveled against them. Where does social entrepreneurialism advocate for stronger regulations of corporations or the free flow of capital? An equity agenda would demand as much. The desire to collaborate closely with campus diversity offices and equity leaders in communities can be thwarted by a lack of common ideas about equity agendas and by working from silos at our universities. The voices calling for a new paradigm arrive from national associations (MacNair, 2016), to critical scholars (Ahmed, 2012), and the prophetic voices of justice echoing through our classrooms and communities.

\section{Articulating Anchor through Cohesion}

Informed and inspired by the demands for racial and intersectional justice, three offices at the University of San Diego came together to integrate programs, align and share budgets, and undertake a practice of joining with each other so that we may more fully join with communities in anchor partnerships. We argued that equity, social innovation, and community engagement 
ought to operate holistically. Communities and students did not move through such spaces in a disjointed way. Our practice must therefore be taken up in community with each other. Our provost supervised all three offices at the time and enabled the construction of a community of practice based on joining. We began to focus on developing capacity among our faculty, students, and community partners to step with us out of the distinct spheres of institutional compartmentalization and into new practices that linked the urgency of equity with the resources of community engagement and social innovation. We developed an authentic community of practice around joining, with the aim of manifesting the anchor mission at a cultural level in our habits and assumptions. At the same time, we were very clearly on our own, garnering interest from some administrators and faculty colleagues, but un-joined by much of the institution.

This changed when a new round of strategic planning began. Our efforts inspired some of the thinking that went into the university's strategic plan, which eventually offered an integrated model of a number of central institutional commitments. This larger platform means that a coherent, unified effort can support fully realizing the anchor mission. We have only begun the cultural work across the institution and the community to raise our collective efforts to a transformative level, and we have had our stumbles, hesitations, and successes.

\section{Opportunities and Challenges in the Practice of Joining}

Your task is not to seek for love, but merely to seek and find all the barriers within yourself that you have built against it. —Rumi

In almost every joining interaction, intentional or otherwise, there lies an opportunity to use the experience as a mirror for self-interrogation. Sometime that mirror offers a sharp, obtuse reflection of oneself to reconcile, and in other instances, there may be a subtler offering that leads you to down a path towards more self-awareness. Through community-engagement opportunities, we are able share clear examples of these opportunities for introspection.

A 20-year-old relationship with staff at the local juvenile detention facility yields a sharp example of community engagement bluntly presenting an opportunity to examine oneself in relation to another and in relation to larger systems dynamics. A student favorite, Juvenile Hall affords students the opportunity to connect with other young adults in very different circumstances. More often than not, the introspective opportunities are subtle but readily apparent, with deliberate questions and thoughtful reflections. What comes up generally revolves around power, privilege, race, and class. Students generally have the room to examine those revelations at their own pace or not at all. Occasionally, the dynamics reveal themselves in ways very disruptive to a student's normal interactions.

During a visit to Juvenile Hall on Columbus Day, a university student encountered an indigenous youth who was willing to share frustration of incarceration and subjugation from a Native perspective. The practice of joining compels the practitioner to see what some may consider an angry outburst as a vulnerable, decisive moment and an opportunity to examine what has emerged. That powerful vulnerability activated the student's own sense of being vulnerable. Being unpracticed, she became paralyzed, retreating to safety of her comfort zone. Her inability to seize this moment to (in the moment or after) stay present, unpack what came up and join in 
that vulnerability is a missed opportunity that is equally apparent on an institutional level. While this episode has limitations for how anchor relationships can be mutually beneficial, as incarcerated youth are not necessarily a stable presence in our ongoing community work, it shows the radical potential of joining as a practice. When colleges and universities accompany community partners, exercising vulnerability and openness, they can step into economic and political associations and collaborations with a deeper, ontological capacity to achieve solidarity.

On an institutional level, when universities attempt to join communities, it too is offered reflections of itself that are difficult to confront. In those moments the prevailing norms and culture prompt defensiveness, technical excuses and fixes, and a doubling down on existing unequal power dynamics. Examples of these relations are also readily available.

Like many campuses over the past two years, USD has been working to welcome and create a safe learning environment for undocumented students, also known as Dreamers. Outreach and enrollment of Dreamers is increasing, and our university welcomes them as it becomes a Changemaker campus. Despite its intention to accompany these young people and join them as they seek education and a place in this society, institutional habits resist authentic practices of joining. Recently the United States Department of Homeland Security (DHS) enrolled in a career fair on campus as an exhibitor, which created a sense of betrayal and fear among the Dreamers and their allies. If the university, as a whole, practiced joining with these students and attended to the issues they face, the urgency of their situation and the legitimacy of their fears may have earned the primacy students and community members thought it deserved. This episode provides an opportunity to explore how institutions can mindfully engage in the practice of joining to help themselves respond, and not react, to moments like these.

In this case, those of us who work within the cohesion model were able to accompany students, the community, and the administration to undertake a course correction and suggest a different path. Community partners who are immigrant advocates alerted our offices to the possible presence of DHS on campus, and we used our support system to notify students of this possibility. Concurrently, student leaders and allies of Dreamers began organizing, leading DHS to back out of the career fair to avoid controversy. Student leaders continued with protests, open forums, and collective reflections, ultimately calling for more transparency and communication regarding threats to the well-being of vulnerable student populations. As with the student at Juvenile Hall, some of our inclinations included defensiveness, shifting responsibility, and offering technical solutions. Self-introspection and joining would come when we brought students and administrators together, and undocumented students seized the opportunity to speak their truth, and administrators joined them in a moment of solidarity. These are the difficult but common interactions on a campus where there exists a viable model of cohesion. The willingness to deliberately and consistently do this work is requisite to join community and truly be an anchor institution committed to equal, democratic, reciprocal partnerships.

\section{Conclusion}

Any university entity can take up the cohesion model, yet it is best undertaken with community partners in the room, resulting from the practice of joining. Inspired by the 2015 student activists' articulation of racial justice as an intersectional project, a cohesion model attempts to 
get the connections right. When undertaking this work as practitioners, we hope readers can identify the actors who must be a part of work, and to join with them to build economic justice and more democratic relationships among those in community. Not every college or university who engages with the anchor mission is ready or interested in institutional transformation. But for those who have done so seriously, and for those who see the stakes in this work regarding the viability of higher education in the future, it is time to recognize the radical potential of the anchor mission and undertake the practice of joining from a deep cultural logic.

The practice of joining engages with an honest struggle for equity rather than proposing solutions that cannot help but serve as window dressing. Criticisms of diversity and inclusion efforts in higher education as excuses for avoiding a confrontation with intersectional equity and racial justice should serve as a warning for milquetoast or piecemeal efforts at community work. Identifying that struggle as an internal, introspective process shifts efforts made by universities from being primarily outward facing to including self-interrogation and an acknowledgement that institutions of higher education can and do perpetuate unequal societal power structures. In doing so, institutions are able to identify, own, and let go of the obstacles that keep them from authentically joining in community.

We hope to inspire ways of working that are just, equitable, democratic, and transformational. 


\section{References}

Ahmed, S. (2012). On being included: Racism and diversity in intellectual life. Durham, NC: Duke University Press. https://doi.org/10.1215/9780822395324

Carey, J.W. (1989). Communication as culture: Essays on media and society. New York, NY: Routledge.

Golom, F. (2018). Reframing the dominant diversity discourse: Alternate conversations for creating whole system change. Metropolitan Universities Journal, 29 (1), 11-28. Retrieved from https://journals.iupui.edu/index.php/muj/article/view/22172 https://doi.org/10.18060/22172

Grossberg, L. (2010). Cultural studies in the future tense. Durham, NC: Duke University Press. https://doi.org/10.1215/9780822393313

Hall, S. (1986). The problem of ideology: Marxism without guarantees. Journal of Communication Inquiry, 10 (2), 28-44. https://doi.org/10.1177/019685998601000203

Heifetz, R.A. \& Linsky, M. (2002). Leadership on the line: Staying alive through the dangers of leading. Boston, MA: Harvard Business Review Press.

McNair, T.B. (2016). The time is now: Committing to equity and inclusive excellence. Diversity and Democracy, 19 (1), 4-7. Retrieved from https://www.aacu.org/diversitydemocracy/2016/winter/mcnair

Mitchell, T. (2008). Traditional vs. critical service-learning: Engaging the literature to differentiate two models. Michigan Journal of Community Service-Learning, 14 (2), 50-65.

Reyes, R. (2016). Engaged pedagogy: Reflections from a Barriologist. Engaging Pedagogies in Catholic Higher Education 2 (1). Retrieved from https://digitalcommons.stmarysca.edu/epiche/vol2/iss 1/1 https://doi.org/10.18263/2379-920X.1012

Wegner, E. (2006). Communities of practice: A brief introduction. Retrieved from http://www.ewenger.com/theory/index.htm

Williams, R. (1989). Resources of hope: Culture, democracy, socialism. London: Verso.

Williams, D.A. \& Wade-Golden, K.C. (2013). The chief diversity officer: Strategy structure and change management. Sterling, VA: Stylus. 


\section{Author Information}

*Esteban del Río, Ph.D.

Associate Provost and Chief Diversity Officer

Associate Professor, Communication Studies

University of San Diego

5998 Alcalá Park

San Diego, Calif. 92110

(619) 260-7455

edelrio@sandiego.edu

Esteban del Río collaborates with partners to advance an equity agenda with the aim of transforming the university and community in the direction of social and economic justice. His teaching and scholarship focuses on the politics and poetics of human difference and unity, with work exploring the production of Latinidad in informational, entertainment, and vernacular discourses. He sits on the governing board of the California Bicycle Coalition, engaging in community-based advocacy around mobility justice. He also serves as the Collegium Board Chair, working on faculty development within the Catholic Intellectual Tradition.

John Loggins

Director of Community Engaged Learning

Karen and Tom Mulvaney Center for Community, Awareness and Social Action

University of San Diego

214 Maher Hall

San Diego, CA 92110

(619) 260-2969

jloggins@SanDiego.edu

John Loggins works collaboratively as part of a team responsible for ensuring that USD is a global and national leader as a community-engaged anchor institution committed to democratic and equitable community partnerships that generate transformative solutions to societal challenges. He earned a masters in Leadership Studies from the University of San Diego and continues to connect his practice of adaptive leadership to his work in community engagement and in his roles as a board member for OG Yoga and as a member of the Place-Based Justice Network Steering Committee. John's commitment to positive social change through community engagement began during his service in Peace Corps Jamaica, where he led an effort to create innovative programming for incarcerated youth. For the past 13 years, John has continued his work in Jamaica by creating and co-creating several international course-based community engagement experiences for USD undergraduate and graduate students.

His continued dedication also shows through his roles as a volunteer (20 years) with American Cancer Society and Seany Foundation.

*Corresponding author 